\title{
Religiosidad en Al-Andalus: el hombre santo en el Islam occidental ${ }^{1}$
}

\author{
FERNANDO RODRÍGUEZ MEDIANO \\ Departamento de Estudios Árabes. CSIC, Madrid
}

El título del curso dentro del cual se enmarca la presente contribución, "Lo constante y lo nuevo en la religiosidad española: las culturas superpuestas", merece un pequeño comentario previo sobre los conceptos de continuidad y ruptura aplicados a la religiosidad en al-Andalus. Una vieja, y hasta cierto punto exitosa, idea defiende una continuidad más o menos significativa entre la época andalusí y el mundo cristiano resultante del proceso que la historiografía tradicional ha llamado "reconquista". La formulación más conocida y elaborada de esta idea de continuidad, sobre todo por lo que se refiere a lo religioso, es la que se puede encontrar en las obras de Miguel Asín Palacios. Asín quería demostrar la influencia del sufismo musulmán en la mística española, influencia que intentó rastrear en las huellas del murciano Ibn al-'Arabī o de Ibn 'Abbād de Ronda en S. Juan de la Cruz, o de los místicos šādilíes en el movimiento de los alumbrados españoles del s. XVI. Esta influencia sería una especie de acto de restitución histórica: al carecer de fuentes de las que nutrirse en el Corán o en la sunna, los místicos musulmanes tuvieron que beber del viejo monacato cristiano oriental. En España se cerraría este bucle secular que acabaría devolviendo al cristianismo los préstamos recibidos a través de las dos vertientes de la mística española del s. XVI, la "ortodoxa" y la "heterodoxa", la de la reforma carmelitana y la de los alumbrados y dejados. La originalidad de la mística española con respecto a Europa se explicaría por esta restitución desde el Islam, cuyos agentes habrían sido los mudéjares y moriscos en su contacto con el cristianismo ${ }^{2}$. Estas ideas

\footnotetext{
1 Una primera versión de este texto fue expuesta públicamente en una sesión del XVIII Curso de Etnología Española "Julio Caro Baroja": Lo constante y lo nuevo en la religiosidad española: las culturas superpuestas, organizado por el Departamento de Antropología de España y América del Instituto de Filología del CSIC. Querría agradecer de forma muy especial a Antonio Cea por haberme invitado a participar en ese curso, y también al resto de los asistentes por sus observaciones.

2 Cfr. M. Asín Palacios, El Islam cristianizado. Estudio del "sufismo" a través de las obras de Abenarabi de Murcia (Madrid: Plutarco, 1931; reed. Madrid: Hiperión,
} 
de Miguel Asín Palacios, que aquí he resumido de forma grosera, son bien conocidas y han sido retomadas en trabajos más recientes, como los de Luce López-Baralt, que quiere ver en S. Juan de la Cruz un modelo del mestizaje cultural propio de la literatura española del Siglo de Oro, síntesis perfecta de las tradiciones occidental cristiana, judía y musulmana ${ }^{3}$, reconociendo, sin embargo, la dificultad para encontrar un mediador del todo convincente (aunque se señala la posibilidad de una influencia musulmana en la cábala peninsular). Significativamente, López-Baralt es autora del estudio introductorio para la edición facsímil de los $\breve{S} a \underline{d}$ dilies y alumbrados de Asín Palacios ${ }^{4}$.

Sin querer entrar en una discusión profunda sobre la mística española, la mística musulmana y las relaciones entre ambas, me parece percibir en los planteamientos citados una dificultad metodológica. Desde luego, las culturas no constituyen paquetes cerrados separados por fronteras infranqueables; sorprende más bien la labilidad de los límites, la ubicuidad de algunos conceptos, la transitabilidad de ciertas ideas ${ }^{5}$. Aquí, sin embargo, el problema se plantea inmediatamente: en primer lugar, porque desde algunos postulados parece que lo que se quiere es, como indica el significativo título de la obra de Asín, "cristianizar el Islam", o, yendo un paso más allá, "españolizar al-Andalus". En este sentido, el uso frecuente entre algunos arabistas españoles de la expresión "España musulmana", o del adjetivo "hispano-árabe", deja al descubierto una ideología de apropiación "colonial" semejante a las descritas por E. Said en su célebre y polémico Orientalism ${ }^{6}$. Por otro lado, la invocación de la "síntesis cultural"

1981), donde se explica que alos ascetas y místicos musulmanes vivían y pensaban conforme a normas de abolengo cristiano" (p. 11). La idea de una influencia posterior del sufismo en la mística cristiana en general y española está desarrollada por extenso en obras como "Un precursor hispanomusulmán de S. Juan de la Cruz", Al-Andalus, I (1933), pp. 7-79, reeditada en un volumen con el significativo título de Huellas del Islam. Sto. Tomás de Aquino. Turmeda. Pascal. S. Juan de la Cruz (Madrid: EspasaCalpe, 1941); o "Šādilíes y alumbrados", Al-Andalus, IX (1944), pp. 321-345; X (1945), pp. 1-52 y 255-284; XI (1946), pp. 1-67; XII (1947), pp. 1-25 y 245-265; XIII (1948), pp. 1-17 y 255-273; XIV (1949), pp. 1-28 y 253-272; XV (1950), pp. 1-25 y 275-288; XVI (1951), pp. 1-15.

3 San Juan de la Cruz y el Islam (2." ed., Madrid: Hiperión, 1990).

4 Madrid: Hiperión, 1990.

5 Cfr., por ejemplo, J. Dakhlia, «La question des lieux communs. Des modèles de souveraineté dans l'Islam méditerranéen,, en B. LEPETTT (ed.), Les formes de l'expérience. Une autre bistoire sociale (París: Albin Michel, 1995), pp. 39-61.

6 M. MARín, "Arabistas en España: un asunto de familia", Al-Qanțara, XIII (1992), pp. 379-393. 
parece pretender la restitución de una cierta idea de españolidad que existió antes de que el aparato funcionarial e inquisitorial del estado moderno impusiera un modelo radicalmente castizo y visigotizante, aplastando el de una España mestiza, única en Occidente, cuyo último y trágico exponente habrían sido los moriscos ${ }^{7}$. La génesis de esta corriente se encuentra, desde luego, en las obras de Américo Castro, y a pesar de su carácter fructífero, lo que se acaba planteando al final es de nuevo el problema de España, y al-Andalus termina, otra vez y por inopinados caminos, españolizado ${ }^{8}$.

El problema que a mí me interesa, sin embargo, es distinto, e incluso opuesto. Me parece que una perspectiva excesivamente centrada en el rastreo transcultural de los orígenes tiende a escamotear el sentido que los actos sociales tienen para sus propios protagonistas ${ }^{9}$. Así, creo que hay que comenzar por situarse en la perspectiva del propio acontecimiento, y restituir las tradiciones que le son propias. Por lo que interesa a este trabajo, el culto a los santos en al-Andalus, es evidente que los actores (los autores de los textos hagiográficos, sus protagonistas, el público receptor, la tradición que retoma y reformula el material narrativo) se consideran, con absoluta evidencia, parte de la tradición musulmana. En este sentido, al-Andalus, como parte de la dār al-Islām, del territorio musulmán, posee poderosísimos vínculos culturales e ideológicos que le unen con el Norte de África y con el resto del mundo islámico, sin que esto signifique, desde luego, negar sus fuertes peculiaridades, empezando por su carácter fronterizo.

7 Cfr., por ejemplo, F. Márquez Villanueva, El problema morisco (desde otras laderas) (Madrid: Ediciones Libertarias, 1998), donde se habla de "la españolidad integral del morisco, en cuanto punto de convergencia de tradiciones y circunstancias de absoluta peculiaridad y sin paralelo en Occidente" (p. 6).

8 Así, un fragmento de un texto de un morisco afincado en Túnez acaba convertido en un insólito "tratado de erotología" español ("Le nace un nuevo texto a la literatura española") en el que se anudan diferentes tradiciones eróticas y espirituales orientales: cfr. L. LÓPEZ-BARALT, Un Kamasutra español (Madrid: Siruela, 1992). Sobre este texto existe, entre otros, un hermoso artículo de J. Oliver Asín, "Un morisco de Túnez, admirador de Lope. Estudio del Ms. $\mathrm{S}_{2}$ de la Colección Gayangos", Al-Andalus, I (1933), pp. 409-450.

9 Sigo aquí la argumentación de un bello libro de A. Hammoud, La victime et ses masques. Essai sur le sacrifice et la mascarade au Maghreb (París: Seuil, 1988), especialmente la de un capítulo titulado "L'anthropologie coloniale du sacrifice et de la mascarade: à la recherche d'une religion perdue" (pp. 33-61). Esta "religión perdida" sería una supuesta religión pagana pre-islámica de la que las mascaradas celebradas en el Atlas serían las últimas trazas. La fiesta queda así, por obra y gracia de la antropología, despojada de su sentido aislámico". 
En este texto voy a basarme fundamentalmente en fuentes hagiográficas, a través de las cuales intentaré dibujar algunos de los rasgos característi$\cos$ de la figura del hombre santo andalusí. Hay que señalar inmediatamente que la tradición hagiográfica andalusí no está excesivamente desarrollada. Para este trabajo he utilizado sobre todo los tres textos que me parecen más característicos. Los dos primeros, la Risālat al-quds de Muhyī 1-dīn Ibn al-'Arabī ${ }^{10}$, y los Milagros de Abū Marwān al-Yuhānisīi de Ahmad al-Qaštāli ${ }^{11}$, son bien conocidos, en especial el primero, y las diferencias entre ambos son notables. Ibn al-'Arabī, el autor de la Risāla, es como se sabe uno de los más importantes místicos musulmanes. Su apodo de alŠayj al-Akbar, "el maestro supremo", así lo atestigua. Nacido en Murcia en 1165, se educó y vivió en distintos lugares de al-Andalus y el Norte de África, especialmente en Sevilla, hasta 1202, año en el que inició la peregrinación a la Meca, y con ella un viaje definitivo al Oriente. Murió en Damasco en $1240^{12}$. El autor del segundo texto, Ahmad al-Qaštălì, es mucho más oscuro ${ }^{13}$. Su obra es un recuento de los milagros de su maestro Abū Marwān al-Yuhānisīi, santo andalusí originario de la localidad almeriense de Ohanes, que murió en 1268 ó 69 en Ceuta. Como se puede inferir por la cronología, que cubre la primera mitad del s. XIII, estamos en el momento de formación del reino nazarí de Granada; de hecho su fundador, Muhammad Ibn al-Ahmar, aparece repetidamente mencionado en la obra. El texto cubre toda la vida de Abū Marwān al-Yuhānisī, y sus estancias en al-Andalus, en el Norte de África y en Oriente, donde viajó largamente para hacer la peregrinación y aprender de maestros orientales. El orden de la narración no es cronológico, salvo, quizás, en su comienzo, cuando se cuenta la conversión y primera iluminación del san-

10 Adopto aquí el nombre de la edición árabe que manejo, a cargo de M. Asín Palacios (Madrid-Granada: Escuelas de Estudios Árabes de Madrid y Granada, 1939). La obra, sin embargo, es conocida por otros títulos, como Risālat rụ̣̄ al-quds, al-Rūḥ al-qudsiyya, Rūḥ al-quds fi munāsaḥat al-nafs, etc. Existe traducción española del propio Miguel Asín, Vidas de santones andaluces. La "Epístola de la santidad" de Ibn 'Arabì de Murcia (2.' ed. Madrid: Hiperión, 1981). Citaré también la traducción inglesa, obra de R. W. J. Austin, Sufis of Andalusia. The Rūh al-quds and al-Durrat al-fākhirah (Berkeley-Los Angeles: University of California Press, 1971), porque añade en el texto fragmentos complementarios de otra obra de Ibn al-'Arabi llamada al-Durra al-fãjira.

11 Ahmad AL-QAŠTĀLİ, Tuhfat al-mugtarib bi-bilād al-Magrib li-man la-bu min alijwān fi karāmāt al-šayj Abī Marwān (Madrid: Instituto Egipcio de Estudios Islámicos en Madrid, 1974).

12 Para la biografía de Ibn al-'Arabī, cfr. especialmente C. ADDAS, Ibn al-Arabì ou La Quête du Soufre Rouge (París: Gallimard, 1989).

13 Cfr. la introducción de Fernando DE LA GRANja a su edición de la Tuhfa. 
to. A partir de ese momento, la continuidad espacio-temporal es abolida en favor de otra lógica narrativa, que acumula anécdotas, historias y milagros cuya misión es demostrar la santidad del maestro.

El tercer texto que utilizaré aquí es el más temprano de los tres, $A l$ Sirr al-mașūn de Ṭāhir al-Ṣadafī ${ }^{14}$. Muy poco se sabe de su autor, que redactó su obra entre 1157 y $1177^{15}$. El libro es una recopilación de biografías de los maestros espirituales que su autor encontró, primero en al-Andalus y el Mágreb, y después en Egipto y el Hiŷāz. Reflejo de los radicales procesos de transformación que vivió el Occidente musulmán durante el s. XII el Sirr constituye uno de los ejemplos más antiguos de literatura hagiográfica en ese ámbito, anterior incluso a otro texto recientemente descubierto, el Mustafād de al-Tamìmi. Se puede decir que, con esta obra, asistimos al nacimiento de una poderosa tradición literaria que no tardaría en consolidarse con textos tan importantes como el Tašawwuf de al-Tādilī ${ }^{16}$.

Como he señalado, el siglo XII es época de revolucionarias transformaciones en el Occidente musulmán, muchas de ellas vinculadas a la historia del movimiento almohade. Una de esas transformaciones es la introducción del sufismo en el Mágreb. Antes de esa fecha, se pueden rastrear algunos ejemplos, como el del cordobés Ibn Masarra, muerto en 931, cuyos seguidores y discípulos sufrieron persecución en época del califa omeya 'Abd al-Raḥmān III ${ }^{17}$. Puede señalarse también, desde el s. X, un aumento en la práctica del ascetismo (zubd) en al-Andalus, y de la producción y transmisión de obras al respecto, aunque a menudo sin relación con el sufismo ${ }^{18}$. Pero la gran eclosión del misticismo se produce, como dije,

14 Al-Sirr al-mașūn fì mā ukrima bi-hi al-mujlișūn, ed. H. Ferhat (Beirut: Dār al-Garb al-Islāmī, 1998). Existe una traducción alemana de Fritz MEIER, "Ṭāhir aṣ-Ṣadafis vergessene schrift über westliche heilige des 6/12 jahrhunderts", Der Islam, 61 (1984), pp. 14-91.

15 Los datos al respecto se encuentran en H. Ferhat, "Al-Sirr al-mașūn de Țāhir al-Ṣadafi: un itinéraire mystique au XII" siècle”, Al-Qanțara, XVI (1995), pp. 273-288.

16 Ibn al-Zayyāt al-Tādilī, al-Tašawwuf ilà riŷāl al-taṣawwuf, ed. A. Tawfíq (Rabat: Kulliyyat al-ādāb wa-l-'ulūm al-insāniyya, 1985). Existe una traducción francesa a cargo de M. de Fenoyl, Regard sur le temps des soufis (Casablanca: Eddif, 1995).

17 Cfr. M. Asín Palacios, Abenmasarra y su escuela. Origenes de la filosofía bispano-musulmana (Madrid: Maestre, 1914); M. FiERro, La beterodoxia en al-Andalus durante el período omeya (Madrid: Instituto Hispano-Árabe de Cultura, 1987), pp. 113118 y $132-140$.

18 Para la evolución del ascetismo en al-Andalus en el s. x y comienzos del XII, cfr. M. MARín, "Zubhād de al-Andalus (300/912-420/1029)", Al-Qanțara, XII (1991), pp. 439-469. Cfr. también, de la misma autora, "Abū Sa'ìd Ibn al-A'rābì et le développement du soufisme en al-Andalus", Revue du Monde Musulman et de la Méditerranée, 63-64 (1992), pp. 28-38. 
durante el siglo siguiente. Así, en la primera mitad del XII, Almería conoció el desarrollo de un importantísimo núcleo de sufies con dos figuras notables: Ibn al-'Ariff e Ibn Barraŷān. Es lo que más tarde será llamada la escuela de Almería ${ }^{19}$. Estamos en época del movimiento almorávide, y las actividades de los dos maestros sufíes les llevaron a ser conducidos a Marrakech para comparecer ante el emir almorávide. Ibn Barraŷān fue ejecutado e Ibn al-'Ariff, aunque perdonado, murió en circunstancias oscuras muy poco tiempo más tarde ${ }^{20}$. Un año después de la muerte de estos dos grandes sufíes almerienses, el célebre Ibn Qasĩ dirigió en el Algarve un movimiento mahdista (término éste, mahdista, que traduciré como milenarista, profético) que puso en graves aprietos al poder almorávide hasta el asesinato de su líder en Silves en $1151^{21}$. Las relaciones de Ibn Qasĩ con el sufismo almeriense son también confusas, y la auténtica importancia de su revuelta mahdista está aún por determinar. Recuérdese simplemente que en Marruecos se había iniciado ya una gran revolución dirigida por otro mahdi, Ibn Tūmart. Se trata del movimiento almohade, que acabaría con los almorávides y crearía de forma arrolladora un inmenso imperio que abarcaba todo el Mágreb, de Marruecos a Túnez, y al-Andalus. No parece casualidad que una tradición historiográfica falsa pero bastante extendida pergeñase un encuentro entre Algacel e Ibn Tūmart en el curso del viaje de éste al Oriente. Recuérdese que Algacel es autor del Ihyyā' 'ulūm al-dinn, imponente enciclopedia religiosa de una enorme influencia a la hora de integrar plenamente el sufismo dentro de la sunna, y que sería quemada en el Mágreb por los emires almorávides.

El siguiente nombre importante en la tradición del sufismo andalusí es desde luego el del más célebre e importante de todos ellos, Muhyī 1-dīn Ibn al-'Arabī, el místico murciano que sería llamado el sello de los santos, el más grande de los maestros (al-Šayj al-akbar). Son varios los caminos que unen la figura de Ibn al-'Arabi con el magisterio de los sufies almerienses ${ }^{22}$. Y sin embargo, la profundidad y complejidad de su obra le convierten en uno de los grandes nombres, no ya sólo de la mística,

19 Cfr. M. Asín Palacios, "El místico Abū-l-'Abbās Ibn al-'Arîf y su "Mahāãsin al-maŷālis", en Obras escogidas (Madrid: Instituto "Miguel Asín", CSIC, 1946), 2 vols., pp. 217-242.

20 Para este episodio y su posible vinculación con la rebelión de Ibn Qasī, cfr. J. Bosch, Los almorávides (ed. facsímil, Granada: Universidad de Granada, 1990), pp. 286 y ss.

21 Cfr. D. R. Goodrich, A 'sufi' revolt in Portugal: Ibn Qasi and his "Kitab khal' al-na'layn" (Tesis Doctoral, Universidad de Columbia, 1978).

22 Para este punto, cfr. C. ADDAS, Ibn 'Arabi, pp. 73 y ss. 
sino de toda la cultura árabo-musulmana. Como ya he señalado, Ibn al-'Arabì es el autor de la Risālat abl al-quds, una recopilación de biografías de santos andalusíes a los que él encontró.

Pero más importante y significado si cabe que el sufismo andalusí es el sufismo norteafricano ${ }^{23}$, en el que varios nombres han sido y son aún objeto de enorme veneración: Abū Ya'zà, o Mulay Bu'azza, un santo beréber e iletrado que no sabía árabe, cuya tumba en Tagiya, en el Atlas, es el centro de una peregrinación anual ${ }^{24}$; Ibn Hirzihim, o sidi Harāzim, enterrado en las cercanías de $\mathrm{Fez}^{25}$; el díscípulo de ambos, el gran santo Abū Madyan, originario de Cantillana, en Sevilla, pero cuyo itinerario espiritual norteafricano le llevó primero a Fez, luego a Bujía y a Tremecén, en cuyas inmediaciones está enterrado. La figura de Abū Madyan es una de las más importantes e influyentes del sufismo occidental, considerado como quṭ o polo de la santidad en su época ${ }^{26}$. La presencia de Abū Madyan es constante en toda la tradición mística posterior, como testimonia, por ejemplo, la obra del propio Ibn al-'Arabī. Un poco más tarde, un importantísimo santo del Rif, Abū l-Ḥasan al-Šãdili fundó una tariqaa, es decir, una vía mística destinada a ejercer una enorme influencia en todo el Islam. A ella se refería, por ejemplo, Miguel Asín Palacios en su ya citada obra Šā b. Mašǐš, el gran santo del Rif, y también, según algunas tradiciones, de Abū Marwān al-Yuhānisīi, el protagonista de la Tuḥfa de al-Qaštālī.

Con todos estos nombres y otros no mencionados aquí, como Ibn 'Abbād de Ronda o Abū l-'Abbās al-Sabtī, se entretejen los hilos de la tradición espiritual del sufismo occidental, cruzando el estrecho en ambas direcciones, remontándose a menudo al Oriente y a otros nombres ilustres, como al-Hallāŷy o Algacel. La palabra que puede ayudar a definir esa

23 Para la evolución del género hagiográfico en Marruecos durante la Edad Media, cfr., de forma general, H. FERHAT, Le Maghreb aux xIlème et XIIIème siècles: les siècles de la foi (Casablanca: Wallada, 1993).

24 E. LÉvI-ProvençAl, "Abū Ya'azzā", The Encyclopaedia of Islam, nueva edición (ER), I, 159. Abū Ya'zà fue contemporáneo de Țāhir al-Ṣadafī, el autor de al-Sirr al-mașūn.

25 A. FaURE, "Ibn Hirzihim", $E F^{2}$, III, 800.

26 H. FERHAT, "Un maître de la mystique maghrébine au XII ${ }^{\mathrm{e}}$ siècle: Abū Madyan de Tlemcen", Le Maghreb aux XII et XIII siècles, pp. 55-78; V. CoRnell, The Way of Abū Madyan. Doctrinal and Poetic Works of Abū Madyan Shu'ayb ibn al-Husayn al-Anșāri (c. 509/1115-16-594/1198) (Cambridge: The Islamic Texts Society, 1996). Para entender el concepto de qutb, "polo", hay que tener en cuenta que entre los santos hay una jerarquía (variable según los autores) en cuya cúspide se encuentra precisamente ese quṭb, cuya existencia es necesaria para la existencia misma del mundo. 
tradición es "cadena", que traduce el árabe isnād, y que se refiere a la transmisión, proceso fundamental que determina el carácter mismo de esa tradición, que se remonta al profeta Muhammad, fuente original de toda legitimidad, y que se reconstruye enteramente con cada transmisor, con cada eslabón de la cadena. Puede decirse que la piedra angular de la tradición es el acto de transmisión individual entre maestro y discípulo ${ }^{27}$. Este concepto de la transmisión es también fundamental para entender cómo se percibe la presencia de lo sagrado en el mundo. Esa presencia tiene un nombre, baraka, palabra que designa a una especie de carisma divino que se revela en las fuentes, en los árboles, en las tumbas, en la naturaleza y en las personas. Carisma de márgenes inciertos, que fluye, que puede acumularse o perderse, que se transmite en fin. Es la presencia de la baraka lo que se reconoce en los hombres santos, que la poseen y tienen a su vez el poder de transmitirla: de transmitirla a los creyentes que peregrinan a su tumba, a los discípulos endurecidos en el servicio del maestro, a los descendientes de santos o del propio profeta Muhammad. Este último extremo es importante, pues justifica la existencia de linajes de santos y, además, la enorme importancia que los jerifes, los descendientes de Muhammad, cobran en distintos momentos y lugares de la historia del Islam.

Una primera definición de santo podría ser, pues, la de "hombre que posee la barakan, o en quien se reconoce la posesión de la baraka. Pero para matizar un poco más esta afirmación, se puede citar un hadiz del Profeta transmitido al comienzo del Tašawwuf de al-Tādilī, que es, como he dicho, una de las primeras y más importantes hagiografías marroquíes. Según este hadiz, y preguntado sobre quiénes son los santos, Muhammad respondió: "Aquéllos que, cuando se los ve, hacen recordar a Dios" ${ }^{28}$. Colocada al frente de una recopilación de 278 biografías de santos, esta tradición constituye todo un programa, en cuanto que expresa, de forma admirable, uno de los rasgos que querría destacar aquí, y es que la santidad, y en general las narraciones hagiográficas constituyen toda una variación sobre el concepto de "mediación". Desde luego, sobre la mediación entre Dios y los hombres, pero también, y como resultado, sobre la mediación política y social. No por casualidad algunas investigaciones clásicas sobre la santidad en el occidente musulmán han puesto de relieve la función de los santos como mediadores en conflictos tribales, y también como mediadores entre la población y el poder político ${ }^{29}$. La me-

27 Cfr. F. R. MEdiano, Familias de Fez (ss. XV-XVII) (Madrid: CSIC, 1995), pp. 51 y ss.

28 AL-TĀDILİ, Tašawwuf, 45; trad. 43. 
diación, sin embargo, no se detiene en este aspecto "pacifista" de la figura del santo, sino que es parte de un complejo de atributos que construyen la autoridad del santo: una autoridad muy efectiva que entra a menudo en competencia o colaboración directa con el poder político.

El santo, un hombre cuya presencia hace pensar en Dios. ¿Cómo un hombre común puede llegar a ese estadio? En el principio, desde luego, está la revelación, la iluminación. La revelación puede ser resultado de un entrenamiento, un objetivo buscado y perseguido, o bien un don inopinado, una revelación repentina y arrebatadora ${ }^{30}$. Con el arrebato se hace presente, desde luego, la arbitrariedad de la divinidad. El entrenamiento y el arrebato, sin embargo, no son incompatibles, sino que aparecen ligados en los itinerarios de santidad: tras la revelación llega el entrenamiento, la ascesis extremada, la búsqueda de los maestros con quienes aprender y a quienes servir. En todo caso, la revelación aparece en el relato biográfico como un momento de ruptura con respecto a la vida pasada. Así, y a propósito de Abū Marwān al-Yuhānisī, la Tuḥfa cuenta cómo un día su madrastra le encargó que le llevase la comida a su hermano, que estaba ocupado en las labores del campo. Al-Yuhānisī era a la sazón un joven despreocupado, sin especial interés por las cuestiones religiosas. Cuando llegó hasta donde estaba su hermano, al cabo de un rato, alYuhạnisĩ escuchó la llamada del almuédano a la oración, y mencionó el nombre de Dios. Al oírle, el hermano de al-Yuhānisī, que estaba medio sordo, cayó en la cuenta de que era viernes, y de que aquélla iba a ser la primera vez en treinta años que iba a perder la oración del viernes. Se quedó entonces desolado, y al-Yuhānisī, para ayudarle, se ofreció a quedarse él a cargo de las labores del campo mientras su hermano iba a rezar. Éste se apresuró a vestirse, y, según se marchaba corriendo, pidió a Dios que arreglase el asunto que había entre Él (Dios) y al-Yūhanisĩ. En ese momento, a éste se le partió el corazón, y se propuso imitar el celo de su hermano en cumplir el precepto de la oración. Después, dice al-Yuhānisī, "cargué la cosecha en las alforjas, y bajé con las vacas hasta el río. Allí lavé mis ropas, y me puse a rezar el resto del día en ese lugar, sin dejarlo ni un solo momento. Al llegar la noche, llevé las vacas y la

29 Recuérdese, por ejemplo, el clásico estudio de E. Gellner, Saints of the Atlas (Londres: Weidenfeld and Nicolson, 1969), donde se estudiaba la función que desempeñaban los linajes de santos en el seno de sociedades tribales segmentarias como mediadores de los conflictos entre los distintos grupos.

30 La mística musulmana diferencia entre el $s a ̄ l i k$, el hombre que sigue la vía mística con esfuerzo, siguiendo los sucesivos estadios hacia la iluminación final, y el mây $\underline{d} \bar{b} b$, el santo arrebatado que cae en trances místicos inesperados e incontrolables; el maŷd $\bar{u} b$ incurre a menudo en comportamientos extravagantes y asociales. 
cosecha a la casa, me fui a la mezquita y allí seguí rezando, sin que mi padre pudiese llevarme de vuelta a casa. Y venían mis amigos, mis parientes y allegados, y me decían: '¿Qué te ha pasado, es que has vuelto loco?', y me reprochaban que me comportara como un niño. Yo, sin embargo, permanecí en aquel estadom. El relato de la conversión es un poco más largo, e incluye la decisión de entregar todos sus bienes a los necesitados y el posterior viaje a la Meca, para cumplir la peregrinación, viaje durante el cual empezaron a manifestarse los primeros prodigios ${ }^{31}$.

Se puede comparar este relato con el que hace Tāhir al-Ṣadafí del inicio de la vida espiritual de un santo llamado Abū l-Walīd Jālid b. Ma'bad al-Šățibĩ:

\begin{abstract}
Había nacido en Xátiva y crecido en ella hasta que llegó a la edad de 10 años. Sus padres le amaban y le proporcionaban todo tipo de cuidados, pero un día salió de su casa, estando aún en ese estado, y vio a un grupo de gente reunida alrededor de un asceta conocido como 'Atĩq al-Mallāh. Éste había huido de ellos, refugiándose en una tienda en ruinas, pero la gente se congregaba en torno a él, aunque él no les hablaba ni les miraba. El jovencito vio aquello y corrió a unirse al grupo para ver qué pasaba. La mirada del asceta cayó sobre él y le pidió que se acercase. Cuando lo hizo, le besó entre los ojos, y el niño concibió un intenso afecto hacia él. Cuando el asceta se levantó, el niño lo hizo con él, y al ponerse a andar, el niño anduvo con él, y así hasta que se acercó a casa del niño. Éste le dijo: "Te conjuro por Dios a que te quedes aquí esperándome hasta que entre en casa y vuelva a salir a por tì. Así lo hizo, y el niño entró en su casa y dijo a sus padres: "Tengo que seguir a este hombre piadoso hoy para ver cuál es su lugar y visitarle siempre que quiera. Quitadme estos vestidos, y ponedme un traje que se parezca a sus andrajos" ${ }^{32}$.
\end{abstract}

En este caso, el momento de la conversión adopta la forma de una elección, elección representada por un beso que sanciona simbólicamente la transmisión de la baraka. El beso iniciático es bien conocido en las ceremonias sufíes, así como la comunicación del carisma a través de los fluidos corporales. El ejemplo citado se puede comparar con el de la iniciación mística del conocido fundador de la cofradía darqāwĩ al-'Arbī b. Aḥmad al-Darqāwì, que un día se cruzó por las calles de Fez con sĩdī al-'Arbĩ al-Baqqāl ( $\mathrm{m}$. después de 1737), que estaba rodeado de curiosos que contemplaban su arrebato místico. Cuando vio a al-Darqāwì, le llamó, le metió la lengua en la boca y le dijo: “'Chupa, chupa, chupa!”. Luego añadió: "Vete. Te hemos dado el Oriente y el Occidente" 33 .

La conversión proporciona al relato hagiográfico una de sus estructuras básicas. En este caso, se trata de la revelación repentina, que supone

31 AL-QAŠTĀLII, Tuhfa, pp. 19 y ss.

32 AL-ṢADAFİ, Sirr, p. 85.

33 Muhammad AL-KatTānī, Salwat al-anfās (ed. litografiada, 3 vols., Fez, 1898-9), I, p. 267. León Africano, por ejemplo, escribiendo sobre el N. de África a principios 
una transformación radical en la vida del elegido. Esta transformación pasa, desde luego, por la renuncia a los bienes, e incluso por una reformulación de los vínculos familiares. La tensión con la familia, que llega a veces a desembocar en una auténtica ruptura, es un topos de las hagiografías, y tiene un sentido fuerte, tanto más cuanto que se trata de una sociedad en la que el individuo no existe sino por relación al grupo al que pertenece, y donde la sociedad se estructura a partir de las relaciones familiares y sanguíneas. Decir, pues, que alguien renuncia a su filiación para iniciar otro itinerario y buscar una filiación distinta significa enunciar una auténtico cambio de vida o, incluso, el nacimiento como un hombre nuevo. Sin entrar ahora en las diferencias entre las distintas formas de acceso a la vida mística, la revelación va seguida, como ya he dicho, de una serie de pasos necesarios: la renuncia a los bienes de este mundo, la búsqueda de maestros y el entrenamiento riguroso en la ascesis, a veces de

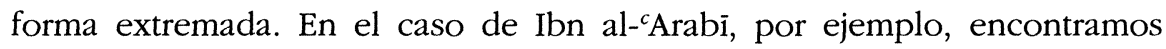
los mismos elementos en su conversión, con la renuncia a los bienes materiales tras haber recibido la iluminación de manos del propio Jesús.

Tras el relato de la conversión, el hagiógrafo procede a la abolición de la cronología en favor de la acumulación probatoria de historias que exhiben la santidad del santo. Son varios los temas involucrados en la definición de la santidad a través de los prodigios. En primer lugar, y ya que me he referido a la santidad como una variación sobre el tema de la mediación, señalaré que en el ámbito de las relaciones del santo con la comunidad, éste ocupa un lugar de intermediario gracias a su relación con Dios. Esa relación con Dios, con la divinidad, tiene lugar en un territorio secreto, escondido de la vista de los demás. De hecho, las alusiones al secreto son constantes en los relatos hagiográficos: Dios está oculto tras un velo que el santo descorre, el santo se aparta, se esconde de la gente buscando el secreto de la comunicación con Dios, etc. Desde ese lugar misterioso y escondido de la unión secreta con Dios, el santo vuelve con el conocimiento de la verdad (haqiqa) y con la autoridad para gestionarla. Así, el santo adquiere una visión especial que le permite penetrar el mundo, llegar a su íntima verdad más allá de las apariencias. En uno de los milagros de al-Yuhānisī, después de que éste hubiese adivinado una cosa

del s. Xvi, habla del "beso lascivo" de las ceremonias sufíes, beso al que él otorga un carácter homosexual; cfr. Description de l'Afrique (trad. francesa A. Épaulard, París: Librairie d'Amérique et d'Orient Adrien Maisonneuve, 1956), I, p. 222. En otros ejemplos más extremados, el discípulo recibe la baraka del maestro ingiriendo su vómito o bebiendo el agua donde sus vestidos han sido lavados. Para todo esto, cfr. F. R. MEDIANO, "Santos arrebatados: algunos ejemplos de maŷdū $b$ en la Salwat al-anfās de Muhammad al-Kattānī”, Al-Qanțara, XIII (1992), pp. 233-256. 
censurable que ocurría a muchos kilómetros de su casa, en Málaga, se apartó con su discípulo Ahmad al-Qaštālī, y le dijo: "Aḥmad, por Dios te digo que no se me oculta ni una pizca de las cosas de la gente, ${ }^{34}$.

La autoridad del santo es, en principio, de tipo cognitivo, basada en ese "no ocultársele nada de las cosas de la gente". Su capacidad para llegar a ese lugar oculto donde está lo sagrado, el secreto de sus secretos encuentros con la divinidad le permite penetrar lo contingente del mundo sensible para llegar a su íntima realidad, la haqiqa, que también permanece oculta tras las apariencias. El autor del Tašawwuf recoge en la introducción de su libro un hadiz del Profeta, que decía "Temed la perspicacia del creyente, pues él ve a través de la luz de Diosn. Otro hadiz, citado inmediatamente después, afirma que Dios tiene servidores que conocen a la gente por su fisonomía ${ }^{35}$. La firāsa, es decir, el conocimiento fisiognómico, es descrito como un don concedido por Dios a los santos. Ibn al-'Arabì, por ejemplo, tratando sobre la firāsa en sus textos místicos, afirma que aquél que posee el don del conocimiento fisiognómico, interpreta las señales naturales del mundo, pero también "otras [que] son espirituales, anímicas, que con la Fe vienen, siendo entonces la vertiente divina, luz de Dios en el ojo de la Percepción del creyente, que conoce así, nada más descubrírsele, lo que ocurre en lo que quiere vislumbrar, sus concatenaciones y las premisas que hasta él conducen" ${ }^{36}$. Para Ibn al'Arabì, esta percepción especial que posee el santo y que proviene de Dios es facultad fundamental para la guía de los novicios, pues el maestro conoce la verdad oculta en el interior de sus discípulos y sabe qué es lo que se debe hacer para mejor conducirlos en su itinerario espiritual. Del maestro, pues, se percibe su absoluta capacidad gnoscitiva. No hace falta añadir que ese conocimiento absoluto se resuelve en un poder asimismo absoluto; y es que las relaciones entre el maestro y el discípulo pueden considerarse como el paradigma de las relaciones de dominación ${ }^{37}$. Uno de los rasgos más específicos de la relación entre el maestro y el discípulo, definida como relación de autoridad es la jidma, es decir, el servicio, pero con el sentido de un servicio absoluto, incondicional, que

34 AL-QAŠTĀLĪ, Tuḥfa, p. 32.

35 AL-TĀDILİ, Tašawwuf, p. 71; trad. p. 64.

36 M. J. Viguera, Dos cartillas de fisiognómica (Madrid: Editora Nacional, 1977), p. 32 .

37 Cito aquí el libro de A. HAmmoud, Master and Disciple. The Cultural Foundations of Moroccan Authoritarianism (Chicago, Londres: The University of Chicago Press, 1997), donde intenta mostrarse cómo las relaciones de autoridad entre el maestro y el discípulo proporcionan un modelo cultural para las relaciones de dominación política en Marruecos, a partir, entre otros factores, del desarrollo del concepto de jidma. 
a menudo implica la realización de las tareas más duras y humillantes. En la Tuḥfa de al-Qaštālì se encuentran algunos ejemplos de servicio. En una ocasión, por ejemplo, un sirviente (jādim) de al-Yuhānisī decidió dejar la casa de éste para viajar a Guadix junto con su esposa, que se dedicaba a la sazón a amamantar a la hija del šayj. Éste le dio permiso, aunque en su fuero interno estaba molesto. Al cabo de un tiempo, sin embargo, el sirviente y su mujer tuvieron que volver a casa del maestro, para satisfacción de éste y su mujer, porque a sólo tres millas de Yuhānis, el rucio que montaban se había parado, y por mucho que le habían azotado, no había vuelto a moverse sino en dirección a casa de al-Yuhānisisi ${ }^{38}$. En otra ocasión, estando al-Yuhānisĩ en Barqa, según sus palabras, "con un grupo de diecisiete sufies (fuqarā') y de peregrinos, tres de ellos cayeron enfermos, y los demás, que estaban sanos, les llevaban las provisiones. Sin embargo, aconteció un problema entre ellos, y los sanos les dijeron a los enfermos: "En realidad no estáis enfermos; tan sólo lo fingís para que os llevemos las cosas". Riñeron por ello, y yo juré que ninguno cargaría con nada salvo yo. De forma que marchaba con ellos, y cuando parábamos amasaba la harina y cocía el pan para ellos, y les daba comida y agua, y me sentaba a su lado. Y cuando nos poníamos en marcha, yo cargaba con las provisiones en mi espalda, hasta que salimos del desierto". La historia se acaba con un toque de humorismo: asaltados los peregrinos por un grupo de beduinos, éstos sólo le intentaron robar el dinero a alYuhānisī, porque, a pesar del esfuerzo y las privaciones, era el único que mantenía el aspecto saludable de un rico comerciante. Ese aspecto saludable era resultado de la baraka que el servicio a los așhāb proporcionaba ${ }^{39}$. Como se puede ver a través de esta historia y de las actividades desempeñadas por al-Yuhānisĩ en servicio de sus compañeros, la jidma, además de la baraka que proporciona, representa toda una inversión del curso natural de la vida masculina.

La vida de un hombre normal ocurre en un ambiente conocido, en el interior de unas redes familiares y de solidaridad estables y previsibles, de un mundo que asegura su reproducción y el bienestar relativo de sus miembros gracias al establecimiento de formas de vida, de producción y de relación social muy rígidas. En un momento determinado de su vida, un hombre desarrolla la potencialidad de los valores viriles con el matrimonio y la reproducción, y con una presencia en un mundo exterior reglado por el lenguaje del honor, es decir, de la violencia y la solidaridad. Un aspirante a santo, sin embargo, se decide a abandonar la certeza de

\footnotetext{
38 AL-QAŠTĀLİ, Tuhfa, p. 114.

39 Id., p. 52.
} 
su mundo para emprender un camino incierto, que le obliga a una redefinición personal, familiar e incluso sexual, con vistas a un improbable éxito. No hay que olvidar que la mayoría de las carreras de aspirantes a santo se resuelven en un fracaso. El relato autobiográfico de algunos de estos santos frustrados nos permite llegar a intuir las terribles obsesiones interiores de una persona que debe competir de forma cruel con otros aspirantes a la santidad, la violenta pasión, los celos, la culpabilidad de quien lucha por la herencia espiritual de su maestro. Finalmente, se puede decir que, en términos sexuales, un discípulo se convierte en una mujer con respecto a su maestro, y como tal le sirve y se ocupa de él ${ }^{40}$. Sólo al final de su itinerario llegará a convertirse en un hombre, llegará a masculinizarse y ser capaz de recomenzar nuevamente por su parte el ciclo de reproducción de la autoridad espiritual. Esta es, desde, luego, una de las claves del sistema, que asegura su existencia y su reproducción: cada actor es a la vez maestro y discípulo en distintos lugares de la cadena social de distribución del poder, y también cada discípulo aspira a convertirse, al final de su entrenamiento, en maestro.

El itinerario espiritual es pues un itinerario de masculinización, de consolidación de los valores de la virilidad, virilidad que se afirma en una sociedad donde el honor es un capital simbólico y la violencia un factor estructural. Esta inversión de roles sexuales es especialmente evidente en el caso de la santidad femenina. Aunque no son tan numerosas como los hombres, sí pueden encontrarse ejemplos de mujeres santas, como alguna de las maestras de Ibn al-'Arabì. De una de ellas, llamada Fāṭima bint Ibn al-Mutannà, cuenta lo siguiente:

Yo serví como fámulo y discípulo en Sevilla a una mujer, de las santas y místicas intuitivas, que se llamaba Fatima [...]. La serví dos años seguidos. Tenía ella, a la sazón, más de noventa y cinco años de edad y, sin embargo, me daba vergüenza mirarle al rostro, pues lo tenía, a pesar de sus años, tan bello y hermoso, por lo regular de sus facciones y lo sonrosado de sus mejillas, que se la hubiera creído una muchacha de catorce años [...] Decía: "Mi Amado me dio, para que me sirva como criado, a la Fãtiha (es decir, la primera azora del Corán) [...]; no comía sino de las sobras que la gente arrojaba a las puertas de sus casas; y aun de estos desperdicios era poquísimo lo que comía ${ }^{41}$.

La historia ilustra perfectamente esa inversión de los roles sexuales a la que me refería, a través del hecho, en principio extraordinario, de que

40 Cfr. F. R. MEDIANO, "Una sociabilidad oblicua. Mujeres en el Marruecos moderno", Al-Qanțara, XVI (1995), pp. 385-402, donde se pueden encontrar ejemplos y referencias al respecto.

${ }^{41}$ Ibn AL-'AraBī, Risāla, pp. 64-5; Vidas, p. 181, y n. 1, donde se traduce el texto que el maestro murciano dedicó a esta santa en su obra más importantes, al-Futūhāāt al-makkiyya. 
un hombre esté al servicio de una mujer. Ello es posible porque, para una mujer, la santidad es un camino de masculinización, en el curso del cual renuncia a su rol dentro del matrimonio y a la frecuentación de los lugares de socialización femenina, y se endurece en la soledad de una ascesis extremada.

La ascesis es, por otra parte, rasgo común de la narración hagiográfica, que abunda en la relación de mortificaciones físicas, de ayunos extremos, representados a menudo por la retirada al desierto, fase de entrenamiento que sucede a la revelación. De uno de los santos que conoció Ibn al-'Arabi éste nos cuenta lo siguiente: "Mi tío paterno [...] entró en el camino de la vida espiritual al fin de su vida, y debió su iniciación a un niño pequeño. Antes de su conversión, acaecida cuando ya había pasado de los ochenta años de edad, ignoraba en absoluto qué cosa fuese este método de vida espiritual. Entregóse, sin embargo, con tal fervor al combate ascético viviendo en los desiertos, que pronto llegó a la cumbre de la perfección" " ${ }^{42}$.

El desierto es omnipresente en el relato de los milagros de Abū Marwān al-Yuhānisī, que alcanzan una rara expresividad al describir la intensidad del conflicto interior desencadenado por las pruebas físicas a las que se sometió. En el Oriente, retirado en un monte nevado, sin más abrigo que un simple saco de pelo que apenas le calienta, Abū Marwān se desdobla en dos: "Me dijo mi alma: "Haz las abluciones con arena, pues si sales morirás". Aquello me enojó, y salí a la fuente. Al llegar a ella, me dijo mi alma: "Lávate los miembros uno tras otro, pues con eso es suficiente". Yo, sin embargo, me tiré a la fuente, me sumergí en ella, e hice mis abluciones. Después, mi alma me dijo: "Corre a la caverna, que está más templada que la mezquita". Yo sin embargo me puse a correr por la nieve [...] hasta que caí desvanecido" ${ }^{43}$. La historia termina con la intervención milagrosa de una leona, que se acerca al cuerpo del santo mientras está desvanecido para darle calor. Los ejercicios ascéticos están omnipresentes en las hagiografías musulmanas y, en general, el alejamiento del mundo para preservar la propia pureza es percibido como un don divino. Así, a uno de los santos biografiados en el Sirr de al-Ṣadafī, 'Abd al-Raḥmān b. 'İsà al-Jazraŷi, le fue concedido el don de no oír las palabras malsonantes que se pronunciaban a su alrededor, mientras que poseía un oído finísimo para escuchar las cosas buenas y decentes que se decían, aunque fuese en voz muy baja ${ }^{44}$. Otro santo, Abū Ŷa'dūn uel alheñero", mencionado por Ibn al-'Arabī, "rogó a Dios le hiciese la gracia

42 Ibn AL-'ARABĩ, Risāla, p. 32; Vidas, p. 109.

43 AL-QAŠTĀLİ̃, Tuḥfa, p. 61. 
de perder la buena fama de que gozaba entre las gentes, y, en efecto, cuando estaba ausente no se le daba crédito alguno, y cuando estaba presente no se le consultaba para nada, y cuando llegaba a un sitio nadie le hacía lugar, y cuando tomaba la palabra ante un grupo lo trataban de necio y aun le pegaban" ${ }^{45}$. Esta historia parece aludir al modelo del malāmatī o malāmĩ, el santo que busca ocultar la verdad de su estado espiritual, buscando incluso la censura de los demás.

De forma que se puede decir que la lógica del itinerario espiritual nos lleva del momento de la iluminación hasta el lugar oculto de la unión mística donde se construye la autoridad del santo, a través de su acceso secreto a la verdad, y desde el que se legitima un orden, un cierto modelo de autoridad, que da forma a las relaciones entre maestro y discípulo. Durante ese itinerario, el aspirante a la santidad se introduce en un nuevo orden simbolizado por el retiro ascético del mundo, y cuyo desarrollo representa una auténtica inversión de los roles sexuales, gracias a la feminización del novicio. Llegado a la posición de maestro, es decir, adquiridos los valores viriles, queda imbuido de una autoridad que le permite el ejercicio efectivo de su papel de intermediación, intermediación religiosa entre Dios y los hombres, sí, pero también política, entre los hombres y el sultán. Este último aspecto político de la actividad del santo está ampliamente subrayado en la Tuhfa de al-Qaštālī. La vida de Abū Marwān al-Yuhānisĩ coincide cronológicamente con el establecimiento del reino nazarí de Granada, y el santo de Ohanes aparece en numerosas ocasiones actuando a favor del primer sultán de la dinastía, Muhammad I, y en los conflictos que resultaron de la desintegración del imperio almohade y también de la presión de los reinos cristianos del norte. En un momento determinado, el propio sultán nazarí busca reunirse con el šayj, que le ayuda en una situación comprometida con los reyes de Castilla y de Aragón ${ }^{46}$. En otra ocasión, vemos a al-Yuhānisī en la corte de Marrakech intentando movilizar a las tribus norteafricanas para combatir en la península. En el curso de esa misma anécdota, se nos dice que, estando en Fez, le llegó la noticia de que los cristianos habían sitiado Algeciras; tras implorar a Dios (los ojos enrojecidos por el llanto), los enemigos levantaron el asedio ${ }^{47}$. Aparece también, y esto es quizás más significativo, enfrentándose a poderes políticos rivales, como Ibn Hūd $^{48} \mathrm{O}$ a determinados funcionarios injustos, a la manera habitual de las

44 AL-ȘADAFİ, Sirr, p. 51.

45 Ibn AL-'ARABī, Risāla, p. 43; Vidas, p. 136.

46 AL-QAŠTĀLİ, Tuhfa, p. 68.

47 Id., p. 70. 
hagiografías, es decir, utilizando el poder de su baraka para castigarlos, hacerles perder su posición o incluso su vida ${ }^{49}$. Así, por ejemplo, al-Qaštali cuenta cómo un fatà llamado Ibn Fațìma llegó a Guadix con plenos poderes de parte del sultán y cometiendo todo tipo de tropelías, deteniendo y robando el dinero a quien se le antojaba, hasta que al final llegó a meterse con un joven honesto y virtuoso que era yerno del jati $b$ de Guadix. Éste fue a suplicar a al-Yuhānisī para que intercediera ante el fatà pero éste, sin hacerle caso, envió al joven a la prisión de Granada. El jațīb volvió al santo llorando, y éste maldijo a Ibn Fațima, que, al día siguiente "amaneció degollado de oreja a oreja [...], y anocheció enterrado en la tierra" ${ }^{50}$.

Este tipo de anécdotas, abundantes en los textos hagiográficos, son algo más que una metafóra que expresa el deseo de una intervención divina que refrene el ejercicio abusivo del poder. A pesar del permanente encarecimiento de un modelo de santidad basado en el ascetismo extremo, el santo tiene una presencia activa en el mundo y sus acontecimientos, incluso en colaboración con el poder político (aunque en teoría se considera que el contacto con el poder es pernicioso) ${ }^{51}$. La santidad en el occidente musulmán es un fenómeno con profundas implicaciones sociales: alrededor de la figura del santo fundador se crean poderosas cofradías con un alto nivel de organización y de movilización, cuya presencia e influencia en lo político y lo económico crecerá progresivamente, sobre todo en el Norte de África, donde la larga duración nos permite contemplar un proceso amplio que en al-Andalus siguió derroteros un poco diferentes o fue simplemente truncado por las circunstancias. El poder de las cofradías religiosas, de las zāwiya-s sufíes, llegará a ser tal en el Norte de África que la historiografía francesa de época colonial acuñaría el potente tópico historiográfico de la crisis marabútica: durante los ss. xv y $\mathrm{XVI}$, las cofradías religiosas habrían liderado un movimiento de reacción contra la ocupación española y portuguesa de las plazas costeras

48 Id., p. 126: Ibn Hūd está bebiendo vino con sus compañeros en Granada, y al-Yuhānisĩ irrumpe en medio de la reunión para romper la vasija de vino. Aunque todos intentan alcanzarle, ninguno puede, e Ibn Hūd llega incluso a amenazar de muerte a todos los murid de al-Andalus si al-Yuhānisì no comparece ante él.

49 Cfr. F. R. MAÑAS, "Hombres santos y recaudadores de impuestos en el Occidente musulmán (siglos VI-VIII/XII-XIV)», Al-Qanțara, XII (1991), pp. 471-496.

50 AL-QAŠTĀLĩ, Tuhfa, p. 79.

51 M. MARín, "Inqibạ̣̄ 'an al-sulțān: 'ulamā' and political power in al-Andalus", Saber religioso y poder politico en el Islam. Actas del Simposio Internacional (Granada, 15-18 octubre 1991) (Madrid: Agencia Española de Cooperación Internacional, 1994), pp. $127-139$. 
norteafricanas y habrían aupado al poder a la dinastía sa'dí ${ }^{52}$. No voy a entrar aquí en el detalle de este tópico, que cito sólo como ejemplo del enorme poder que las organizaciones religiosas van a adquirir en situaciones posteriores de mayor institucionalización. Cabe recordar también que en determinados estudios sobre santidad en el Mágreb es ya un hábito citar los trabajos de P. Brown e intentar aplicar su modelo de explicación del nacimiento del culto a los santos en la Antigüedad Tardía cristiana, modelo que habla de una crisis del sistema de patronazgo clásico, y de una reorganización de las relaciones clientelares alrededor de la figura del santo y de sus reliquias. En este proceso, gran parte del vocabulario político habría pasado al mundo religioso. Un similar trasvase de conceptos entre el vocabulario político y el religioso puede detectarse en el mundo de la santidad musulmana, y el propio uso de la expresión wali Allāb para denominar a los santos evoca la amicitia latina ${ }^{53}$.

El tema de las relaciones entre la política y la santidad es complejo, pero se puede afirmar, en principio, que la autoridad y el poder son fundamentales para entender cómo se construye la figura del santo, no ya sólo por el aspecto institucional que acabo de recordar, sino porque en las relaciones del santo con sus discípulos y con el resto de la comunidad entra en juego el sistema global de las relaciones de dominación. Al-Qaštāli narra en la Tuhfa una de las historias que le ocurrieron a al-Yuhānisĩ en su periplo iraquí, concretamente en Bagdad, y con un maestro oriental, sidi Šalìl b. Miyāḥ:

Estando de viaje en Bagdad, con el santo Šalil b. Miyāḥ, éste le invitó a cenar a su casa. En el camino entre la zāwiya y la casa del santo, pasaron por un lugar frecuentado sólo por fuqarā', y donde había una especie de farol, a la luz del cual adivinaron la presencia de dos personas en actitud obscena (se entiende, homosexual). El santo bagdadí apagó inmediatamente la luz, mientras decía: “El poder y la fuerza pertenecen sólo a Dios", repitiéndolo varias veces ante la extrañeza de Abu Marwān al-Yuhānisī, que pensó para sí, reprobando la actitud de sidi Šalil: " ¿Y con un simple "El poder y la fuerza pertenecen sólo a Dios" se corrige lo reprobable (al-munkar)? ¿Dónde se quedan entonces la ejecución con la espada, o los azotes, o la quema con el fuego? ¿Y dónde la lapidación?" Por la

52 Esta tesis encuentra su expresión más acabada en la obra clásica de A. Cour, L'établissement des dynasties des Chérifs au Maroc et leur rivalité avec les turcs de la Régence d'Alger. 1509-1830 (París: Leroux, 1904). Recuérdese que los sacdíes llegaron al poder en Marruecos durante la primera mitad del s. XVI, y que son la primera gran dinastía que hizo del jerifismo, de la ascendencia profética, el principal elemento de su ideología legitimadora.

53 Cfr. H. Touati, Entre Dieu et les bommes. Lettrés, saints et sorciers au Maghreb (17e siècle) (París: École des Hautes Études en Sciences Sociales, 1994). 
noche, tras la oración, dos hombres se adelantaron de la masa de los fuqarā'y se acercaron al šayj, para decirle: "Venimos de Persia, y nos llamamos Fulano y Fulano. Nuestra conducta era reprobable, hasta que se hizo pública y tuvimos que huir de nuestro país. Seguimos con la misma conducta, hasta que fuimos descubiertos y azotados [...]". Así que dijimos: "Lo único que nos queda es vender nuestras ropas y disfrazarnos de fuqarā', ir con ellos y frecuentar su compañía para ocultarnos, y así quizás Dios se apiade de nosotros gracias a ellos y sigamos su camino, abandonando el nuestro". Así que permanecimos durante seis meses ocultos entre los fuqarā', hasta que esta noche nos sorprendió el šayj Šalīl en una actitud reprobable, y en ese momento nos arrepentimos en Dios.

El propio Abū Marwān al-Yuhānisĩ cuenta el final de la historia: «Entonces observé con el espíritu que la luz del arrepentimiento brillaba en sus rostros. El šayj Šalil volvió su rostro hacia mí y me dijo: "Así se corrige lo reprobable. Tú eres magrebí, y por eso sólo piensas en el azote, en la espada, en el fuego o en la lapidación"” 54 .

No es extraño encontrar, en esta época, alusiones al carácter riguroso de los magrebíes, a diferencia de la moderación propia más bien de los ulemas y hombres de religión orientales. La anécdota citada es ejemplar de este topos, dentro siempre del estilo un tanto pintoresco que tiñe todo el relato de la Tuhfa de al-Qaštālí. En este texto en concreto se hace alusión a al-amr bi-l-macrūf, es decir, "ordenar el bien y prohibir el mal", precepto fundamental de la hisba, de "la censura de costumbres", que constituye todo un modelo de intervención en la vida social y, como tal, es el lema legitimador de innumerables movimientos religiosos y políticos en el Magreb. En el milagro citado, la polémica se plantea en cuanto a los métodos de aplicación de esa censura de costumbres, y se pone de manifiesto la relación dialéctica entre dos modelos, que yo llamaría de momento el modelo del perdón y del arrepentimiento, y el modelo de la represión y el castigo. En la elaboración de ambos subyace una doble concepción política de la idea de justicia. En una de ellas, el castigo tiende a afianzar el sistema de dominación y el orden establecido, afirmando incluso la posibilidad de la arbitrariedad en el castigo que, precisamente por oponerse al principio de proporcionalidad, confirma lo indiscutible de dicho sistema. Esta concepción tiene que ver con la vieja idea de que es preferible un poder, aunque sea injusto, que el desorden. En la otra dirección, se pone en juego la idea de compasión como opuesta a la tiranía, la idea de amor, en definitiva, como concepto político, que permite al final el desarrollo de la práctica de la gracia, del perdón real. La ten-

54 AL-QAŠTĀLİ, Tuhfa, pp. 40-1. Agradezco a Halima Ferhat sus indicaciones para la correcta interpretación de este pasaje. 
sión entre ambos modelos es sólo teórica y, responde a diversas facetas de creación de la autoridad del santo.

En primer lugar, está el hecho del evidente poder sobrehumano que se manifiesta en los milagros. Con ellos, los santos perturban el orden natural y el orden político, las coordenadas del tiempo y del espacio, y adquieren autoridad sobre los ŷinn y sobre los fenómenos naturales. Un prodigio que se repite constantemente en los relatos hagiográficos, por ejemplo, es el de la realización de larguísimos desplazamientos en muy poco tiempo: la posibilidad, por ejemplo, de estar en Guadix e ir hacer la oración a la Meca en un solo día. Al-Yuhānisī cuenta cómo, estando un día en Ceuta "pensaba en el vuelo de los santos, y cómo harían para volar por el aire, y se me ocurrió que abrían sus brazos en el aire como hacen los pájaros con las alas. Entonces escuché un ruido en el aire, como si algo cayese en picado, y al levantar la cabeza vi a un hombre sentado, con las manos sobre las rodillas, que me dijo: "Así, 'Abd al-Malik, así", ${ }^{55}$. Como se ve por esta historia, la abolición del orden natural está dotada a menudo de una fuerte corporeidad, de un aspecto muy físico que la hace extremadamente presente. Esta expresividad es cualidad fundamental de los milagros, a veces la más importante: otro de los textos de la Tuḥfa cuenta cómo un al-Yuḥānisĩ joven se embarcó como polizón en un barco, y los marineros, al descubrirlo, lo maltrataron y arrojaron al mar. Al-Yuhānisĩ nadó hasta la orilla, pero el barco se hundió y sus sesenta y cinco marineros murieron ahogados. El castigo era tan desproporcionado que cuando se presentó ante otro santo, Abū l-'Abbās al-Šățibī, éste le reprendió y le dijo: "¿Estás satisfecho de este asunto? ¿Te complace que Dios mate por tu causa a sesenta y cinco hombres que te han perjudicado?». Al final, al-Yuhānisĩ tuvo que pedir perdón a Dios ayunando durante dos meses seguidos ${ }^{56}$. La desproporción entre la ofensa recibida y el castigo propinado es obvia, se hace explícita en el mismo relato y parece querer expresar la inapelable autoridad del santo y, en fin, la arbitrariedad de lo sagrado, que se impone como propiamente incomprensible.

La autoridad del santo se construye, pues, en principio, desde esta parte terrible de su poder que tiene mucho que ver con su modalidad de actuación en la vida pública, corrigiendo y castigando los abusos de los poderosos, de los agentes corruptos del sultán, aconsejando a éste y ayudándolo frente a sus enemigos. Como se ve, este poder del santo, a menudo terrible, es descrito como indiscutible y como inapelable, de la misma manera que lo es su autoridad sobre sus discípulos. Ya he señala-

55 Id., p. 46.

$56 \quad$ Id., p. 132. 
do, páginas atrás, que la relación maestro-discípulo constituye todo un modelo para las relaciones de autoridad, y que ese modelo se basa en gran parte en la jidma, el "servicio" al maestro que supone una aceptación de su voluntad, e incluso una inversión de los roles sexuales del discípulo. Pero este modelo de autoridad no sólo se fundamenta sobre la terrible capacidad de acción del santo, esto es, sobre la coerción, sino que pone en juego un conjunto de pasiones que liga al santo con sus seguidores; emociones que, como parte de un sistema de autoridad, tienen un carácter también político. Tenemos, en principio, la fuerte emotividad que se desprende de las historias de milagros, incluso las más terribles, que apelan más a la emoción que a la comprensibilidad. Se trata de reproducir la intensa emotividad que produce la presencia de los santos, sus gestos extraordinarios, sus palabras que, medio desveladas, permiten entrever la verdad en la que el maestro está oculto; un estilo, en fin, que niega la univocidad de las palabras y que es capaz de aludir al sentido oculto del mundo, de las cosas. Esta es, a lo que parece, la cualidad expresiva propia de los santos. De uno de los más importantes santos de la tradición hagiográfica norteafricana, Abū l-'Abbās al-Sabtī, se nos dice que "se le había dado capacidad de lengua y poder de palabra. Nadie discutía con él sin ser reducido al silencio. Pronto a la respuesta, tenía siempre preparado el Corán y los pasajes con que argumentar, atrapando del todo los corazones, fascinando al pueblo y a la élite con su elocuencia. Cuando alguien venía para contradecirle, se marchaba sometido a él y rendido a sus palabras" ${ }^{57}$. De otro de los maestros de Ibn al-'Arabī, llamado Abū 'Abd Allāh Muhammad al-Jayyaț, el místico murciano nos dice:

Abū Abd Allāh [...] abandonó el mundo, para ingresar en la vida espiritual [...] La piedad filial que tenía hacia su madre fue tal, que se consagró a su servicio como criado, hasta que ella murió. El temor de Dios era el estado de ánimo que le dominaba; tanto que, cuando hacía oración, oíase desde lejos el zumbido de su corazón al latir en su pecho, y pronto sus ojos derramaban abundantes lágrimas. Casi siempre silencioso, siempre triste y muy meditabundo, lanzaba a menudo ayes y gemidos [...] Nunca se le veía con otra actitud que con la cabeza baja y los ojos fijos en el suelo. No sólo no gastaba con nadie bromas, sino que ni aun frecuentaba el trato de persona alguna [...] Probóle Dios con la pobreza y con úlceras purulentas, y sobrellevó paciente estas pruebas. Fue un místico de admirable vida interior y de altos ideales. Cuando yo era pequeño, ya lo quería apasionadamente [...] Cuando entraba en la mezquita, todo el que le veía le tenía un temor mezclado de respeto (bāba-bu kull man ra'ā-bu). Jamás observé que se adelantase a dirigir la palabra a nadie, ni respondía tampoco a quien le hablaba, a no ser por necesidad imprescindible [...] Sus visiones

57 AL-TĀDILİ, Tašawwuf, p. 451; trad. p. 325. 
en sueños eran verídicas. Soportaba el hambre largo tiempo. Pasaba la noche en vigilia y el día en ayunas ${ }^{58}$.

En esta historia salen a relucir alguno de los temas tradicionales de las hagiografías, y a los que ya he aludido, como el abandono del mundo y el "servicio" como entrenamiento espiritual. Pero me interesa subrayar sobre todo la fuerte emotividad descrita en la historia; la emotividad en la actitud del santo, constantemente transido del temor de Dios y derramando abundantes lágrimas, pero también la emotividad que el santo provoca en su entorno: el temor mezclado de respeto en la gente que le encontraba en la mezquita y el amor que despertaba en su discípulo Ibn al-'Arabī. Estos dos sentimientos, amor y temor, resumen perfectamente el pathos ligado a la autoridad del santo. Son precisamente estos elementos pasionales los que permiten la legitimación del sistema de autoridad más allá de la simple coerción: gracias a ellos se produce la interiorización del sistema; esto es, convierten al sistema en "verdad". En la Tuhfa, al-Qaštālī describe así lo que sentía por su maestro al-Yuhānisĩ y lo que éste despertaba en sus discípulos: “Yo le amaba [...] por su afabilidad, por la belleza de su rostro, la dulzura de su expresión, por su inclinación a frecuentar las gentes honestas. Trataba a cada persona según sus cualidades, y ensanchaba el pecho de las gentes por la vastedad de sus conocimientos, hasta que Dios inspiró en el pecho de los hombres un amor absoluto hacia él, de forma que apenas se podía encontrar a alguien que le mirase sin que su alma quedase prendida de él" ${ }^{59}$.

Alrededor del amor y del temor se produce una elaboración teórica que los convierte en conceptos políticos, a partir de los cuales se construye una determinada noción de obediencia, que se puede detectar tanto en el ámbito de la santidad como en el ámbito político ${ }^{60}$. De hecho, la figura del santo y del sultán son en muchos conceptos equiparables, y la historia nos proporciona abundantes ejemplos en los que ambos colaboran o entran directamente en conflicto ${ }^{61}$. Un caso claro que coincide cronológicamente con los textos que me ocupan aquí es el de Ibn Tūmart, el mahdi de los almohades, cuya figura es en gran medida reconstruida

58 Ibn AL-'ARABī, Risāla, pp. 26-7; Vidas, pp. 96-8.

59 AL-QAŠTĀLİ, Tuhfa, p. 37.

60 F. R. MEDIANO, "L'amour, la justice et la crainte dans les récits hagiographiques marocains", Studia Islamica (en prensa).

${ }^{61}$ Cfr., por ejemplo, AL-ȘADAFĩ, Sirr, p. 47, a propósito de Sulaymān al-Mașmūdĩ: "Los reyes del Mágreb [...] le obedecían de igual manera que él obedecía a Dios, y le amaban como él amaba a Dios". 
legendaria e interesadamente en las fuentes posteriores. En una de ellas, descrito como santo y como jefe político a la vez, se narran los comienzos de la expansión de su movimiento, y la violentísima represión que ejerció sobre los enemigos y sobre todo tipo de disensión interna. En ese momento, y tras enseñar su profesión de fe ('aqĩda) los beréberes mașmūda, se nos dice que "creció su admiración por él, y se infiltró en sus corazones el amor hacia él, y en sus cuerpos la obediencia" ${ }^{62}$. Como se ve, esta frase evoca admirablemente, y de forma muy sencilla, la vinculación entre la obediencia, el amor y el temor en el lenguaje religioso y político, materializados en la persona del Mahdi almohade.

Las hagiografías andalusíes pertenecen, con todas sus peculiaridades, a una tradición propiamente musulmana. El s. XII nos coloca, en el Occidente islámico, en un momento crucial y revolucionario, asociado en gran medida al surgimiento y expansión del movimiento almohade. Uno de elementos de la nueva situación es la creación de una tradición sufí específicamente magrebí. Los textos hagiográficos ilustran cómo se crea un modelo de santidad y cuáles son sus rasgos más específicos. En el presente texto me he centrado en aquéllos que sirven para construir un determinado modelo de autoridad. Este modelo se basa en principio en la función mediadora: oculto en la intimidad de Dios, el santo aparece dotado de una capacidad sobrenatural de penetración en el mundo, de . conocimiento de la verdad por debajo de las apariencias. A esta capacidad gnoscitiva hay que añadir la de su poder efectivo de acción sobre el mundo a través de sus milagros, muchos de ellos relacionados con el sultán y con el castigo de los abusos del poder político. Esta capacidad de acción es a menudo descrita de forma terrible y sobrecogedora. Es precisamente la fuerza pasional de la presencia del santo la que nos lleva a otro componente de su autoridad, el componente emotivo, que manipula los conceptos de amor y temor desde una perspectiva política. Todo ello sirve para construir un determinado modelo de autoridad que comparten los discursos religioso y político, y que está extendido por toda la sociedad. Uno de los de los principios esenciales de este modelo es el "servicio" debido al maestro, que proporciona un fundamento cultural a todo el sistema de autoridad. Esta creación textual y teórica de la autoridad del santo tiene su correlato en el proceso histórico de institucionalización de las cofradías sufíes, que con el tiempo llegarán a constituirse en uno de los poderes mas importantes del Mágreb. Pero el fundamento de todo el

62 'Abd al-Wāhiid AL-MARRĀKUŠĩ, al-Mu ŷib fi taljiss ajbār al-Magrib, ed. M. S. al-'Aryān y M. al-'A. al-'Alamī (7." ed., Casablanca: Dār al-Kitāb, 1978), p. 274; trad. española A. Huici Miranda (Tetuán: Editora Marroquí, 1955), p. 145. 
sistema es, precisamente, su verdad profunda, es decir, su capacidad de interiorización y de reproducción: la simple emoción ante el espectáculo tremendo de la santidad.

Los siglos XII y XIII son fundamentales para la expansión del sufismo en el Occidente musulmán y para la creación de una tradición hagiográfica puramente magrebí. En este artículo se utilizan tres textos hagiográficos andalusíes de esa época para analizar cómo se construye la autoridad del hombre santo desde una doble perspectiva: la del miedo a la acción del santo y la del amor que inspira. A través de estas pasiones se puede rastrear la existencia de un modelo de autoridad que es a la vez religioso y político.

Hagiographical literature in Western Islam is abundant from the 12th-13th centuries onward, and is tied to the introduction and expansion of sufism in al-Andalus and Morocco. In this paper I analyse three hagiographical texts from al-Andalus in order to understand how the authority of a holy man is constructed from two perspectives: fear of his miraculous power and love inspired in his followers. Through these two passions, love and fear, one can infer the existence of a political and religious pattern for authoritarian relationships in Western Islam. 